\title{
Networking
}

\section{Barriers and opportunities to developing research capacity in primary care trusts: the views of staff attached to a primary care trust}

Roger A Harrison Public Health Directorate, Bolton Primary CareTrust and Evidence for Population Health Unit, University of Manchester, Bolton, UK

In the UK, the Department of Health recognizes the importance of research activity to improve patient care, but the amount of research activity relating to primary care is scant. Few have considered managerial and organizational aspects relating to developing research capacity in primary care and none have examined this from the perspective of organizations responsible for managing primary care at a local level. Yet these organizations have a critical role in increasing the amount of appropriate health services research and developing a research culture. A qualitative analysis of focus group workshops was performed to identify issues associated with developing research capacity within a primary care trust (PCT) covering a single local authority borough in England. All staff attached to the PCT were invited to attend facilitator-led focus groups and asked to consider from an individual and organizational perspective: What will enable them to increase the use of and participation in research? What barriers exist? What opportunities exist or could exist to develop this in the PCT? Themes were identified using content analysis based on written records from the focus groups. Issues relating to developing research capacity were grouped into the following categories: What is research? Training; Resources; Managerial; and Organizational issues. Research was not seen as an integral component of the daily or routine work of most people in a health care organization. Managerial and organizational issues were a considerable barrier to developing research capacity. Lack of appreciation and support for research by managers and lack of structures to facilitate research within the organization prevented research capacity being developed. Primary care management organizations need to work with service managers to encourage the incorporation of research activity into the routine work of staff. Greater dialogue is needed between individuals, service managers and academics to ensure that appropriate research is carried out to support the organization in meeting its explicit objectives. More work is needed to understand the perceptions of research from a managers' perspective and to develop constructive ways to gain their support for a research agenda.

Key words: primary care; public health; research and development; research capacity; training 


\section{Introduction}

In England and Wales, the National Health Service (NHS) recognizes the value of research in improving patient care (Department of Health, 1993; 1996; NHS Executive, 1996; 1997), increasingly directing research to meet health care priorities across the country (Secretary of State for Health, 1997). Paradoxically, while the majority of people are cared for through primary care organizations, primary care has been heavily criticized for scant research activity (NHS Executive, 1997). Studies examining some of the reasons relating to lack of research activity have focused on specific professional groups, predominantly doctors or nurses (Robinson and Gould, 2000; Parahoo and McCaughan, 2001; Jones et al., 2003). Few have considered the role of an organization in developing a research culture integrated within daily practice. Moreover, no previous work has considered the role of organizations responsible for the provision and delivery of primary care and other services, across a defined local population. In England and Wales, such activities are now the responsibility of the primary care trust (PCT).

PCTs were introduced in England and Wales in 2000. These organizations are responsible for improving the health of a geographically defined population, often between 100000 and 200000 people, by assessing need and securing the provision of appropriate health care services and providing many services themselves. PCTs will manage $75 \%$ of the total NHS budget (Department of Health, $2001 ; 2002$ ). As such, they are key to developing a research culture within their own organization and within organizations that they contract services too, such as general practice (Mant,1998). This study was designed to provide a greater insight into the barriers and opportunities, at an individual and organizational level, to help develop a research culture throughout the PCT.

\section{Methods}

The study took place at Bolton PCT. The metropolitan borough of Bolton is in the north-west of England and the PCT serves a population of around 200000 adults. The study used a qualitative methodology to explore barriers and opportunities to developing a research culture. Those invited to attend focus group workshops included all staff working directly for the PCT, those working in partnership with the PCT and general practitioners (GPs) and primary care nurses on contract to the PCT. During the facilitated workshops participants were asked to consider three pre-specified themes at the level of an individual (i.e., themselves) and organization (i.e., their team, department, the PCT overall): What will enable you to increase the use of and participate in research? What are the barriers in relation to this? What opportunities exist or could possibly exist to develop research capacity? An assigned person collected data by writing down the verbal responses. Content analysis was used to identify emerging themes based on the written data (Mays and Pope, 2000; Pope et al., 2000). The findings were fed back to participants in the form of a report.

\section{Results}

In spring 2003, 46 people attended two workshops. Participants included primary health care practitioners, professionals allied to medicine, public health practitioners, service managers, and representatives from social services, the local authority and GPs. It was not possible to calculate how many individuals had been invited to attend the workshops because many of the invitations were sent using department email groups rather than inviting named individuals. Moreover, many work activities associated with the PCT are done in partnership with a range of organizations. As such, the number of participants as a proportion of the total number of people involved in providing/planning health care in the borough of Bolton is not known.

Themes emerging from the workshops could be grouped into five main areas: What is Research? Training; Resources; Management; and Organizational issues.

\section{What is research?}

Confusion surrounded the term 'research', seen as an add-on activity and not 'quite the real world', often forming part of a postgraduate qualification, rather than an integral component of everyday work. The need for research was questioned, with one 'knowing from experience what to do' and 
others seeing it as a pointless exercise as 'the results are always changing'.

\section{Training}

Training was a key driver to encouraging a research culture but accepting that 'we won't become R\&D specialists overnight'. Training needed to be provided locally, rather than in other towns and flexibility in terms of training opportunities was essential. Training sessions were also regarded as being influential in supporting multiprofessional and multi-agency working, and facilitating networking and the sharing of ideas.

\section{Resources}

Resource issues focused on lack of funding or 'know[ing] who has the pots of money'. Lack of dedicated time for research activity was a significant barrier, supporting the notion that research is additional rather than part of one's usual role. Partnership working was a possible way to reduce the burden of research activity by spreading the load, and those with an idea should not always be expected to do the research as people who 'might not have the idea for a topic, [could be] willing to take on other organizations' ideas'. Inadequate working environments and information technology (IT) were a significant barrier to research with 'hot desking ... not appropriate for doing research' and the 'shortage of access to computers for "work" activities mean that there's no space for doing R\&D'.

\section{Managerial}

There was a general feeling that managers were not interested in supporting research as 'they are just bothered about reducing waiting lists' and 'didn't see that research was money well spent'. 'Managers should value our research' but usually they did not provide much 'real' commitment or support to it. Staff were looking for their managers to give them motivation along with 'leadership and vision', but this did not happen at the moment. One suggestion was that research should be included on staff personal development plans (PDP) and work objectives. That way, managers would be encouraged to provide the necessary support and resources for staff to meet these obligations.

\section{Organizational}

A number of people thought that a total culture change was needed within the organization to have 'real commitment to a research agenda'. This needed supporting from the top, with vision and direction. One suggestion to encourage research activity was that it should be formally contracted into service provision. Moreover, past research had 'been done in isolation and wasn't used' so that future strategies needed to ensure local dissemination and incorporation into the decisionmaking process.

\section{Discussion}

The current study identified major barriers and possible opportunities at individual and organizational levels to developing research capacity across a PCT. Themes emerging from the focus groups reflected components previously identified in a consultation process as being key to a research capacity development plan (North American Primary Care Research Group Committee, 2002). This plan proposed that research capacity building should focus on issues relating to training, funding, infrastructure and linkages across different organizations/professionals. The findings from our study also reflected individual or systems issues used to identify the needs of GPs to developing research capacity (Jones et al., 2003).

Our study was carried out in a single PCT and participants in the focus groups may not represent the views of everyone working with the PCT. The study methodology was not developed in terms of generalizability, but to seek greater understanding about some of the barriers and opportunities to a research culture within this type of organization. Bolton PCT is involved in a relatively large number of research projects, compared with many other PCTs at least in the north-west of England. It is not certain how our findings would reflect the views and experiences of people working in more or less research active PCTs. Anecdotally, our own experience suggests that some of the barriers to a research culture expressed though this study, are similar to those in other PCTs and in other health care organizations. Other studies, e.g., have found that health care workers fail to see how research affects aspects of daily work (Hicks, 1996). Work has also identified a lack of time, resources and 


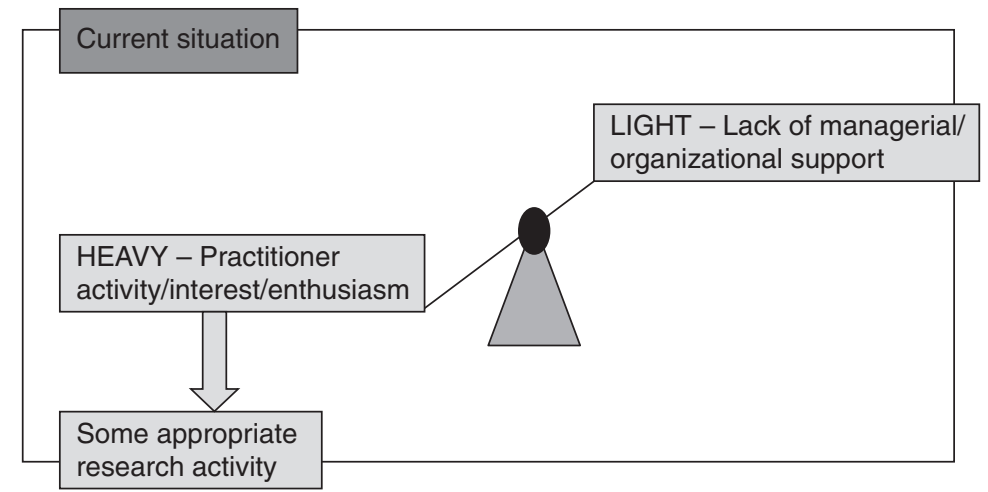

Figure 1 Current and possible future scenario in terms of practitioner and managerial/organizational support for research capacity in a health care organization

support as barriers to engaging in research activity (Strange, 1996; Jowett et al., 2000; Jones et al., 2003) and different interpretations of the term 'research' is not new (Greenhalgh and Douglas, 1999).

The novelty of our study relates to managerial and organizational issues, in terms of developing research capacity. It was apparent that many people appeared to be interested in developing research capacity as part of their work, but lacked managerial and organizational support. Consequently, we suggest that the current commitment by staff to a research agenda is unlikely to be sustained out with appropriate and adequate managerial and organizational support (Figure 1). Research enthusiasts may go on to seek employment elsewhere in research supportive organizations, or resort to a position where research is something that people do elsewhere. Similarly, managers are failing to seize opportunities to obtain information and evidence to support their own decision making through local research activity. Ultimately, this may be detrimental to patient care. Part of the problem may be because researchers are not given opportunities to show the 'real' value from their work to their managers and organization overall, and without this, research sceptics will continue. Moreover, researchers need to ensure that their research questions address issues or problems to be resolved by their managers and the overall department (Whitford et al., 2000). This in itself will help foster managerial support to the research agenda (Pearson and Jones, 1997). Previous work suggests that managers and practitioners are interested in developing research capacity for different reasons (Le May et al., 1998). Whilst not a direct block to research activity, potential conflict could exist, which could be reduced by being more explicit about the reasons for supporting research activity.

A key recommendation arising from this work is to develop systems within the PCT and partner workers/agencies to encourage better dialogue particularly between research enthusiasts and research sceptics. Work is needed to integrate the research agenda within the mainstream structures of the PCT. This will need to draw on specific local examples to highlight the advantages to local service providers and policy-makers of fostering an integrated research culture and the dangers of failing to embrace this across the organization. Work is also needed to encourage those responsible for monitoring and evaluating the activities of PCTs and other health care organizations, to develop performance-managed objectives which incorporate elements relating to a research agenda. This could include positively rewarding those taking on this remit. More detailed research is also needed, in which the attitudes of health care managers towards research capacity are explored to help develop in future, constructive ways to engage their support.

\section{Acknowledgements}

I would like to thank all the participants for taking part in the focus group workshops, Alan Cowie and Nazima Sahar for helping to arrange the workshops, and Bolton PCT for supporting this work. 


\section{References}

Department of Health. 1993: Report of the taskforce on the strategy for research in nursing, midwifery and health visiting. London: Her Majesty's Stationery Office.

Department of Health. 1996: Primary care: delivering the future. London: Her Majesty's Stationery Office.

Department of Health. 2001: Shifting the balance of power within the NHS: securing delivery. London: Department of Health.

Department of Health. 2002: Shifting the balance of power: the next steps. London: Department of Health.

Greenhalgh, T. and Douglas, H.R. 1999: Experiences of general practitioners and practice nurses of training courses in evidence-based health care: a qualitative study. British Journal of General Practice 49, 536-40.

Hicks, C. 1996: A study of nurses' attitudes towards research: a factor analytic approach. Journal of Advanced Nursing 23, 373-79.

Hicks, C., Hennessy, D., Cooper, J. and Barwell, F. 1996: Investigating attitudes to research in primary health care teams. Journal of Advanced Nursing 24, 1033-41.

Jones, A., Burgess, T.A., Farmer, E.A., Fuller, J., Stocks, N.P., Taylor, J.E. and Waters, R.L. 2003: Building research capacity. An exploratory model of GPs' training needs and barriers to research involvement. Australian Family Physician 32, 957-60.

Jowett, S.M., Macleod, J., Wilson, S. and Hobbs, F.D.R. 2000: Research in primary care: extent of involvement and perceived determinants among practitioners from one English region. British Journal of General Practice 50, 387-89.

Le May, A., Mulhall, A. and Alexander, C. 1998: Bridging the research-practice gap: exploring the research cultures of practitioners and managers. Journal of Advanced Nursing 28, 428-37.

NHS Executive. 1996: Towards clinical effectiveness. London: Department of Health.
NHS Executive. 1997: National working group on $R \& D$ in primary care. Final Report. Bristol: NHS Executive.

North American Primary Care Research Group Committee on Building Research Capacity and the Academic Family Medicine Organizations Research Subcommittee. 2002: What does it mean to build research capacity? Family Medicine 34, 678-84.

Mant, D. 1998: R\&D in primary care - an NHS priority. British Journal of General Practice 48, 871.

Mays, N. and Pope, C. 2000: Qualitative research in health care: assessing quality in qualitative research. British Medical Journal 320, 50-52.

Parahoo, K. and McCaughan, E.M. 2001: Research utilization among medical and surgical nurses: a comparison of their self reports and perceptions of barriers and facilitators. Journal of Nursing Management 9, 21-30.

Pearson, P. and Jones, K. 1997: Primary care - opportunities and threats. Developing professional knowledge: making primary care education and research more relevant. British Medical Journal 314, 817-24.

Pope, C., Ziebland, S. and Mays, N. 2000: Qualitative research in healthcare: analysing qualitative data. British Medical Journal 320, 114-16.

Robinson, G. and Gould, M. 2000: What are the attitudes of general practitioners towards research? British Journal of General Practice 50, 390-92.

Secretary of State for Health. 1997: The new NHS: modern, dependable. London: Her Majesty's Stationery Office.

Strange, K.C. 1996: Primary care research: barriers and opportunities. Journal of Family Practice 42, 192-98.

Whitford, D., Jelley, D., Gandy, S., Southern, A. and Van Zwanenberg, T. 2000: Making research relevant to the primary health care team. British Journal of General Practice $50,573-76$. 